\title{
Is There Any Evidence for a Role of Local Treatment in Cholangiocarcinoma?
}

\author{
Arndt Vogel ${ }^{\mathrm{a}} \quad$ Oliver Dudeck $^{\mathrm{b}}$ \\ ${ }^{a}$ Department of Gastroenterology, Hepatology and Endocrinology, Hannover Medical School, Hanover, Germany \\ ${ }^{\mathrm{b}}$ Department of Radiology and Nuclear Medicine, University of Magdeburg, Magdeburg, Germany
}

\section{Keywords}

Cholangiocarcinoma - Local therapy ·

Locoregional therapy · Intervention

\section{Summary}

Background: Most cholangiocarcinomas (CCA) are locally advanced and unresectable at the time of diagnosis. Currently, chemotherapy combining gemcitabine with a platinum agent is the recommended first-line treatment regimen for advanced biliary tract cancer. However, median overall survival is only approximately 1 year. As the hepatic tumor burden is the limiting factor for the prognosis of these patients, local tumor control is essential. Methods: We present and discuss the current evidence for such therapy options for patients with CCA. Results: Local and locoregional therapies have been shown to be well tolerated and can contribute to tumor control in the context of a comprehensive oncologic treatment strategy, and may prolong survival of patients with advanced CCA. Unfortunately, only few high-quality clinical trials are available. Conclusion: Randomized prospective clinical trials enrolling larger numbers of patients need to be carried out to elucidate the precise value of these treatments alone as well as in combination with systemic chemotherapy.

\author{
Schlüsselwörter \\ Cholangiozelluläres Karzinom · Lokale Therapie · \\ Lokoregionale Therapie · Intervention
}

\section{Zusammenfassung}

Hintergrund: Das cholangiozelluläre Karzinom (CCA) ist zum Zeitpunkt der Diagnose meist lokal fortgeschritten und damit inoperabel. Derzeit ist die Kombination von Gemcitabin mit einem platinhaltigen Agens das empfohlene Erstlinienbehandlungsschema für das fortgeschrittene CCA. Dennoch beträgt das mediane Gesamtüberleben damit nur etwa 1 Jahr. Da die Lebertumorlast der limitierende Faktor für die Prognose dieser Patienten darstellt, ist eine lokale Tumorkontrolle essenziell. Methoden: Wir präsentieren und diskutieren die aktuelle Datenlage solcher Behandlungsoptionen für Patienten mit CCA. Ergebnisse: Lokale und lokoregionale Therapien haben eine gute Verträglichkeit und können zur Tumorkontrolle im Rahmen einer umfassenden onkologischen Behandlungsstrategie beitragen, die das Überleben von Patienten mit fortgeschrittenem CCA verlängern kann. Leider stehen derzeit nur wenige qualitativ hochwertige klinische Studien zur Verfügung. Schlussfolgerung: Um die genaue Wertigkeit solcher Behandlungen alleine sowie in Kombination mit systemischen Therapien beurteilen zu können, bedarf es der Durchführung prospektiv randomisierter klinischer Studien mit großen Patientenzahlen.

\section{KARGER \\ Fax +497614520714}

Information@Karger.com

www.karger.com
(C) 2014 S. Karger GmbH, Freiburg 1662-6664/14/0304-0254\$39.50/0

Accessible online at: www.karger.com/vim
Prof. Dr. med. Oliver Dudeck

Department of Radiology and Nuclear Medicine University of Magdeburg

Leipziger Straße 44, 39120 Magdeburg, Germany

oliver.dudeck@med.ovgu.de 


\section{Introduction}

Cholangiocarcinoma (CCA) is the second most common primary liver cancer. In Western countries, the incidence is increasing, and currently up to $1 / 100,000$ people are diagnosed with CCA per year [1]. CCA defines all tumors originating from bile duct epithelium, including intrahepatic CCA (ICC) and extrahepatic CCA (ECC), as well as gallbladder carcinoma. ECC can be divided into perihilar carcinoma and distal ECC. Radical resection is the only curative treatment option. However, in cases with potentially curative surgery, 5-year survival rates of only $25-30 \%$ are reported, indicating an unmet need for multimodal treatment strategies to improve the cure rate of patients with CCA [2]. In the palliative setting, the treatment intent is to extend life expectancy, relieve symptoms of obstructive jaundice, and improve quality of life. Subclinical or frank cholangitis is associated with increased morbidity and mortality, and endoscopic biliary drainage is an established procedure for palliation of unresectable malignant hilar biliary strictures. In metastatic disease, chemotherapy improves quality of life and survival, and gemcitabine with cisplatin represents the standard of care based on recently published phase II and III clinical trials [3]. However, all patients ultimately progress on this therapy, and hence clinical trials with new and better agents and innovative treatment strategies are essential to expand the existing treatment options for patients with CCA. Thus, minimally invasive treatment options are gaining attention, such as photodynamic therapy (PDT) which consists of a photosensitizing agent in combination with laser irradiation, intraductal and percutaneous radiofrequency ablation (RFA), and high-dose-rate brachytherapy (HDR-BT), as well as transarterial approaches such as hepatic arterial infusion (HAI) chemotherapy, transarterial chemoembolization (TACE), and ${ }^{90}$ yttrium radioembolization (RE). Here, we present and discuss the current evidence for these local and locoregional therapy options for patients with CCA.

\section{Therapy Options for Cholangiocarcinoma}

\section{Photodynamic Therapy}

One of the mainstays in the treatment of CCA is to relief obstructive jaundice through placement of biliary stents, which has been shown to improve symptoms and prevent infectious complications such as cholangitis. To further improve local control in CCA, PDT has been first introduced as a treatment modality in 1991. PDT is based on the relatively specific accumulation of photosensitizers, such as porphyrins, in dysplastic or malignant cells (fig. 1). Approximately $24-48 \mathrm{~h}$ after administration, non-thermal laser light of appropriate wavelength activates the photosensitizer. Laser activation creates toxic oxygen radicals that induce microvascular disturbances and degradation of membranes and lysosomes of the malignant cells [4]. PDT can be subsequently repeated depending on local tumor control and re-obstruction. Up to date, evidence for the use of PDT in CCA is based on three published randomized trials, three meta-analyses, and several retrospective, mostly single-center reports [3,5-8]. In the pivotal clinical trial by Ortner et al. [5], PDT led to significant improvement in quality of life and prolonged overall survival from 3.3 to 16.4 months in 20 patients compared to 19 controls treated with stenting alone. These data were confirmed in a subsequent study with 32 patients in whom PDT increased median survival from 7 to 21 months [6]. Subsequently, several retrospective studies added more evidence that PDT is superior to stenting alone in the treatment of non-resectable CCA. These observations were summarized in a recently published meta-analysis which included six studies with 170 patients who received PDT using similar administration techniques compared to placement of either plastic or metal stents alone [9]. In this metaanalysis, PDT was associated with a statistically significant increase in median survival, improvement in Karnofsky scores, and a trend for decline in serum bilirubin. In summary, evidence is still rather low, but these studies indicate that PDT is associated with a promising trend toward improved survival as well as improvement in quality of life compared to stenting alone despite the significant heterogeneity between the different groups and potential selection bias.

However, there is clear evidence for a significant survival benefit for CCA patients treated with a combination of gemcitabine and cisplatin chemotherapy based on a large phase III clinical trial [10]. Therefore, the value of PDT has to be considered in the context of state-of-the-art chemotherapy. In this regard, Talreja et al. [11] recently reported their outcome in 55 patients with unresectable CCA, who received either Photofrin ${ }^{\circledR}$ (porfimer sodium; Pinnacle Biologics, Inc., Bannockburn, IL, USA)-based PDT alone or in combination with chemotherapy and/or radiation between 2004 and 2010 [11]. 26 patients received chemotherapy and/or radiation therapy, whereas 29 patients were treated with PDT alone. In all patients, plastic stents were systematically placed following PDT. Median survival of patients treated with PDT alone was 190 days compared to 257 days for patients additionally receiving chemotherapy and/or radiation. Due to the small sample size, the difference in survival was not statistically significant. However, in line with this study, the not yet fully published Photostent-02 study revealed similar findings. In the UK Photostent-02 trial, 92 patients with confirmed CCA were randomized to receive PDT plus stenting or stenting alone. Overall survival was significantly reduced to 5.6 months for PDT plus stenting compared to 8.5 months for stenting alone (hazard ratio 1.8; $\mathrm{p}=$ 0.027 ). At this point, the reasons for the poor overall survival in the PDT group remain elusive. However, only 9 patients in the $\mathrm{PDT} /$ stenting arm compared to 19 patients in the stenting alone arm received subsequent chemotherapy. Overall survival was significantly improved among those who had chemotherapy 

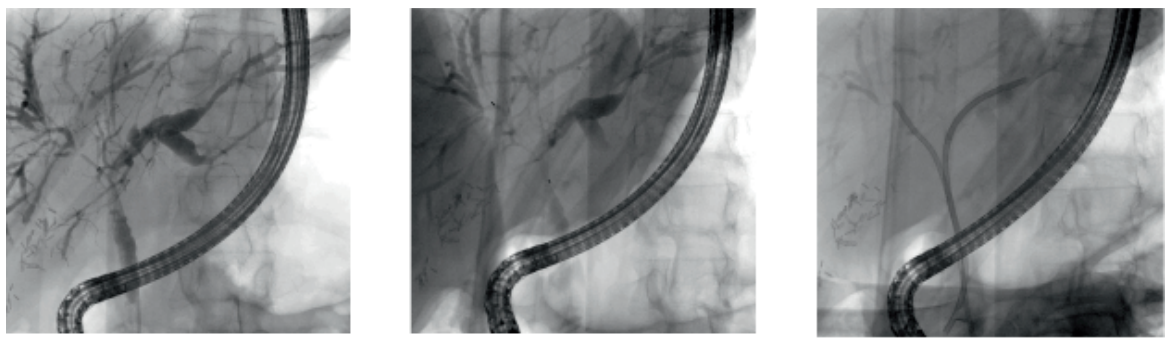

Fig. 1. Endoscopic images before, during, and after photodynamic therapy (PDT; top row) as well as endobiliary radiofrequency ablation (eRFA; bottom row). In 2012, an interruption of the contrast medium was seen at the right ductus hepaticus, which was treated with PDT and stent placement. In 2013, the tumor progressed into the left ductus hepaticus, which was subsequently treated with eRFA and stent placement.
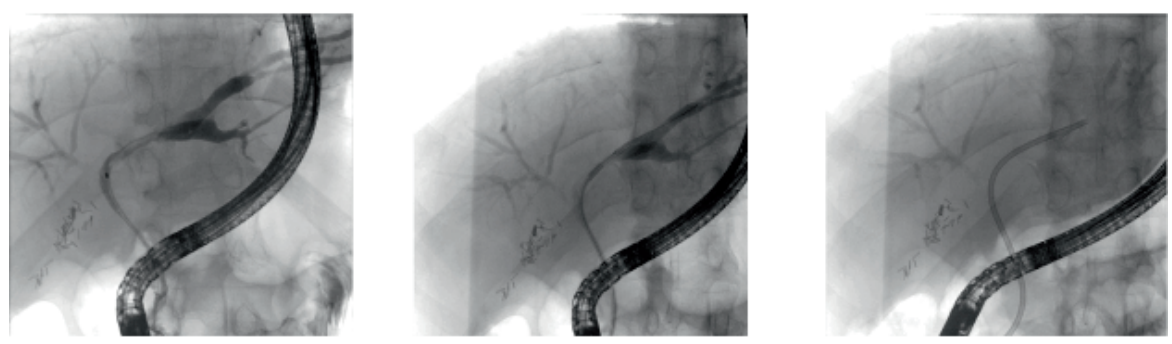

compared with those who did not (11.1 vs. 4.8 months; $\mathrm{p}=$ 0.001 ), suggesting that lack of subsequent palliative chemotherapy may partly explain the detrimental effect in this trial [12]. Very recently, results of a phase II trial from Korea were published in which 43 patients with unresectable hilar CCA were randomly assigned to receive either PDT plus the oral fluoropyrimidine S-1 or PDT alone [13]. In this trial, PDT plus S-1 was associated with a significant improvement in overall survival (17 vs. 8 months; $\mathrm{p}=0.005$ ) and progression-free survival (10 vs. 2 months; $\mathrm{p}=0.005$ ) compared with PDT alone, strongly suggesting that effective tumor control with systemic chemotherapy is required in CCA.

Most trials suggest that PDT only induces minimal side effects, with the most frequently encountered adverse effect being phototoxicity to the skin. However, a significant number of patients, more than $50 \%$ in some reports [14], subsequently develop infectious complications such as cholangitis or hepatic abscesses due to stenting complications or as the result of necrosis associated with PDT. Infectious complications due to PDT may not only have direct consequences on survival but may also delay exposure to chemotherapy in CCA patients.

Together, these data indicate that PDT may be of value in highly selected patients. Additional prospective studies are clearly required to specifically analyze the impact of PDT on the morbidity and mortality of patients with CCA, specifically in the context of systemic chemotherapy. In the recently published guidelines for the treatment of CCA from the British Society of Gastroenterology, PDT is not recommended for routine use based on the most recent data [53].

\section{Endobiliary Radiofrequency Ablation}

One of the problems associated with PDT is related to its phototoxicity requiring patients to avoid exposure to sun- light for 4-6 weeks. Another innovative technique to ensure continued biliary drainage is endobiliary RFA (eRFA) (fig. 1). Percutaneous RFA has been previously employed in the treatment of ICC as discussed below. ECC, however, are mostly not amenable to percutaneous RFA treatment, and eRFA may be an attractive alternative. Similarly to percutaneously applied RFA, eRFA is a minimally invasive technique that uses high-frequency alternating current to heat tissue to the point of coagulation, leading to local tumor destruction over a length of approximately $2-3 \mathrm{~cm}$. One of the first published studies included 21 patients with unresectable biliary obstruction due to pancreatic and biliary cancer [15]. Successful self-expandable metal stent placement was achieved in all patients following eRFA allowing initial biliary decompression in 21 patients. Moreover, 30-day stent patency was achieved in 20 patients, and at 90-day follow-up stent patency was preserved in 16 of 19 living patients. Subsequently, it was shown in 39 patients that eRFA may also be safely performed via the percutaneous transhepatic route with an over-the-wire technique [16]. In this study, all but 1 patient had patent stents at the time of last follow-up or death. Both series did not reveal any new unsuspected safety concerns. Together, the so far available evidence suggests that eRFA is safe and feasible and may prolong stent patency in patients with malignant biliary obstruction. Randomized clinical trials are now required to determine how eRFA can be integrated in the multimodal treatment of CCA.

\section{Radiofrequency Ablation}

Percutaneous image-guided RFA is a minimally invasive technique that uses high-frequency alternating current to heat tissue to the point of coagulation with the aim of local 
Fig. 2. a T1- and b T2-weighted magnetic resonance image of a 61-yearold woman with a centrally located intrahepatic cholangiocarcinoma (arrows) with preferentially left-sided cholestasis (asterisk).

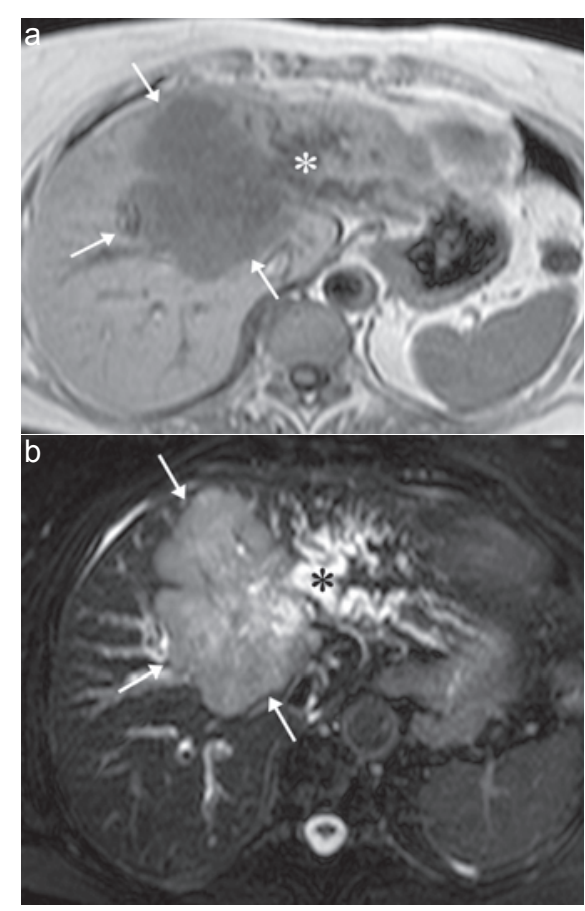

Fig. 4. A T1- and B T2-weighted magnetic resonance image 2 years and 1 month after high-dose-rate brachytherapy showing a marked decrease in tumor size (arrow) and regressive cholestasis.
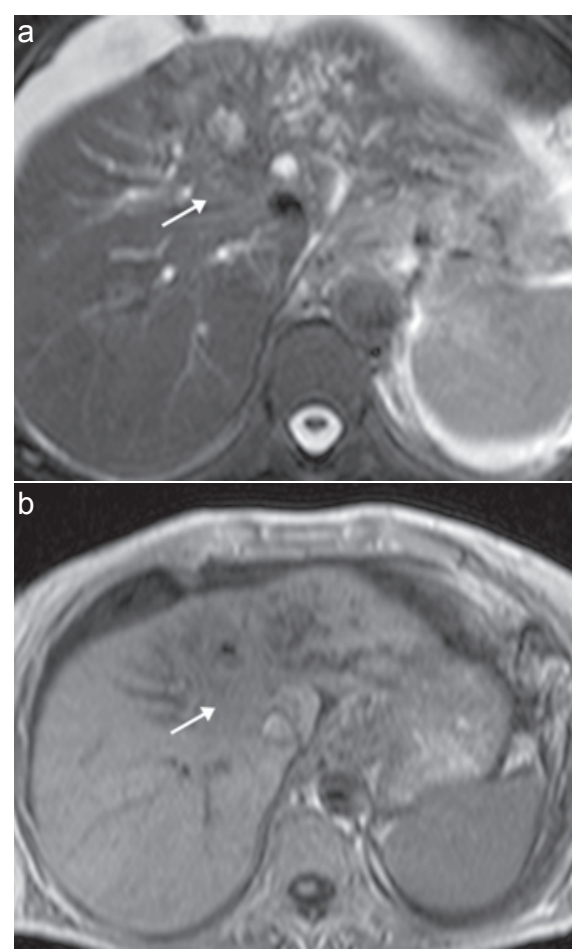

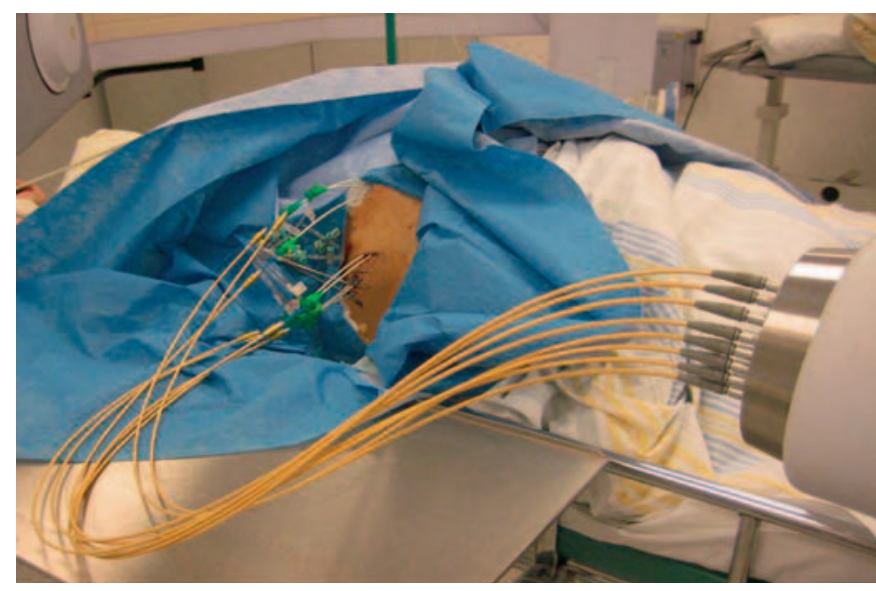

Fig. 3. Image of the patient with a total of 8 catheters placed intratumorally for high-dose-rate brachytherapy with a tumor-enclosing dose of 15 Gy. The closed-end brachytherapy catheters are already connected to the afterloader (microSelectron ${ }^{\circledR}$; Nucleotron, Elekta, Stockholm, Sweden).

tumor destruction. RFA has been reported to be safe and effective in the local control of hepatic malignancies in patients considered unsuitable for surgical resection, regardless of tumor vascularity [17-19]. In a study including 13 patients with 17 primary ICC (10 tumors $<3 \mathrm{~cm}, 5$ tumors $3-5 \mathrm{~cm}, 2$ tumors $>5 \mathrm{~cm}$ ) treated with RFA, local control was achieved in $88 \%$. The median overall survival period was 38.5 months [20]. In the two treatment failures, the tumors were more than $5 \mathrm{~cm}$ in diameter. Thus, RFA may provide successful local tumor control in patients with intermediate $(3-5 \mathrm{~cm})$ or small $(<3 \mathrm{~cm})$ ICC.

\section{High-Dose-Rate Brachytherapy}

In HDR-BT, liver malignancies are treated by percutaneous placement of brachytherapy catheters under cross-sectional image guidance followed by a single intratumoral highdose-rate irradiation with iridium-192 of typically $15-20$ Gy using an afterloading technique (figs. 2-4) [21, 22]. This technique was established in 2002 and has been subsequently used with promising outcomes, e.g., in colorectal cancer metastases or hepatocellular carcinoma [23, 24]. HDR-BT has been proven valuable especially in those lesions unfavorable for RFA because of large diameters (up to 10-13 cm), complex shape, or closeness to central bile ducts or vessels [25]. Specifically in patients in whom RFA is not feasible owing to larger tumor size $(>5 \mathrm{~cm})$ or adjacent larger vessels which can cause convection of heat (cooling effect) during thermal ablation, possibly resulting in incomplete ablation, HDR-BT may be an alternative option [26]. As ICC regularly arises from larger bile ducts, which are adjacent to the major vessels, such a condition is encountered frequently in this tumor entity so that a considerable number of ICC lesions are not suitable for RFA.

Schnapauff et al. [21] evaluated outcomes after repeated interstitial HDR-BT (27 sessions) in 15 patients with unresectable ICC, who did not show extrahepatic metastasis and suffered from limited hepatic disease only. The median size of liver lesions was $5.25 \mathrm{~cm}$ (range 1-12 cm). Median local tumor control, including repeated local ablations, was 11 months with a median survival of 21 months after primary diagnosis. We have evaluated the clinical outcome in a total of 55 patients with unresectable ICC treated with a tailored therapeutic approach combining systemic with advanced image-guided local 
or locoregional therapies such as RFA, HDR-BT, HAI chemotherapy, TACE, or RE, with the majority of patients $(n=45$; $83 \%$ ) being treated with HDR-BT (own submitted but yet unpublished data). 8 (15\%) patients showed complete remission, $21(38 \%)$ partial remission, $8(15 \%)$ stable disease, and 18 (33\%) progressive disease with a median overall survival of 33.1 months (95\% confidence interval 16.5-49.8 months) from the time of first diagnosis. Remarkably, these results were comparable to those after surgical resection with curative intent with a median survival of 27-36 months [27-29].

\section{Hepatic Arterial Infusion Chemotherapy}

In HAI chemotherapy, the chemotherapeutic agent is delivered through a (micro-)catheter-port system into the hepatic artery and implanted via the common femoral artery as described elsewhere [30], which can be performed on an outpatient basis. This method minimizes systemic side effects (e.g. nausea and vomiting) and maximizes the chemotoxic effects of the drugs on the hepatic malignancy $[31,32]$. The rationale to apply HAI chemotherapy to patients with CCA is strengthened by the high hepatic extraction on the first pass of some drugs that reach the bile canaliculi at high concentrations and by the finding that the blood supply of the upper biliary tree and gallbladder derives from the hepatic artery $[33,34]$. There are only a few retrospective reports with small patient numbers published to date concerning the effectiveness of HAI chemotherapy in these rare tumors [35-37]. Among them, an analysis of 32 patients represents the largest trial, but a variety of biliary tract carcinomas (i.e., 17 patients with ICC and ECC and 15 patients with gallbladder carcinoma) were included. The HAI chemotherapy protocol consisted of a combination of 5-fluorouracil (5-FU), cisplatin, and folinic acid. In comparison to patients treated with supportive measures or with systemic chemotherapy alone, this regimen showed rather good activity and an improvement in survival. However, it was not a randomized prospective trial. Thus, any conclusions from these data are of limited value. In a phase II trial, 30 consecutive patients with advanced or metastatic biliary tumors were treated with epirubicin and cisplatin administered as a bolus into the hepatic artery on day 1 , combined with systemic continuous infusion of 5-FU per day from day 1 to day 14, every 3 weeks [31, 38]. In this heterogenous patient group, the overall response rate was $40 \%$ including 1 complete response and 11 partial responses with a median patient survival of up to 13.2 months.

\section{Transarterial Chemoembolization}

TACE includes two therapeutic strategies to target solid tumors - the intra-arterial application of a chemotherapeutic drug combined with hepatic artery embolization. Severe systemic toxicity is limited because only about $15 \%$ of the agent administered appears in the periphery, resulting in a favorable side effect profile as compared with systemic chemotherapy. Conventional TACE has been studied as a palliative treatment option for CCA with protocols using lipiodol in combination with mitomycin $\mathrm{C}$, gemcitabine, cisplatin, or doxorubicin. In a small study of 15 unresectable ICC who received palliative TACE with a mixture of lipiodol and mitomycin C, median survival was reported to be 16.3 months [39]. In a study by Vogl et al. [40], 115 patients were treated with a total of 819 TACE using different protocols (mitomycin C alone, gemcitabine alone, gemcitabine and mitomycin $\mathrm{C}$ or gemcitabine, mitomycin $\mathrm{C}$ and cisplatin), which resulted in a median overall survival of 13 months. Another trial investigated the effect of TACE using mitomycin C, doxorubicin, and cisplatin in 62 patients with ICC or adenocarcinoma of unknown primary reporting a median survival of 20 months from diagnosis and 15 months from the time of first TACE [41]. In a study conducted by Park et al. [42], 72 patients with untreated unresectable CCA received a cisplatin-based TACE as first-line therapy. Survival after diagnosis was measured and compared with that of patients who received supportive therapy only. Median survival was 12.2 months for the TACE group and 3.3 months for the supportive treatment group. Taken together, these studies showed a significant survival benefit for patients with CCA treated with TACE compared to patients who received best supportive care. However, no definite conclusions can be drawn from these data, since none of the studies were prospective comparative trials.

\section{Drug-Eluting Bead TACE}

Chemoembolization with drug-eluting beads (DEB) combines a controlled drug release from beads with a reduction in blood flow by embolization. In a small retrospective comparison of 9 patients who underwent DEB-TACE with oxaliplatin associated with systemic chemotherapy applying oxaliplatin and gemcitabine, overall survival was with 30 months significantly increased as compared to 12.7 months in a historical group of 11 patients treated with chemotherapy only [43]. Another small but prospective trial compared TACE with DEB loaded with doxorubicin $(\mathrm{n}=11)$ with palliative care or systemic chemotherapy $(n=9)$ [44]. A response rate of $100 \%$ according to RECIST criteria was observed in the locoregional treatment group. Median survival was with 13 months significantly prolonged as compared to 7 months in patients who received palliative care or chemotherapy. DEB-TACE using beads containing irinotecan was investigated in another study of 26 patients with histologically proven ICC and compared retrospectively with conventional TACE with mitomycin $\mathrm{C}$ and to systemic chemotherapy with oxaliplatin and gemcitabine [45]. Local tumor control was achieved in $66 \%$ of patients receiving DEB-TACE that resulted in a median overall survival of 11.7 months compared with 5.7 months in patients treated with conventional TACE 
and 11.0 months in patients receiving systemic chemotherapy. Despite the fact that the study was retrospective, DEB-TACE is feasible and may be more effective than conventional TACE in the treatment of ICC. However, again results of prospective trials are lacking. Thus, no definite conclusions ought to be drawn.

\section{${ }^{90}$ Yttrium Radioembolization}

$\mathrm{RE}$ is another promising catheter-based liver-directed modality approved by the U.S. Food and Drug Administration for the treatment of patients with primary and metastatic liver cancer [46, 47]. For this interventional technique, microspheres of glass or resin, impregnated with the isotope ${ }^{90} \mathrm{yttrium}$, are infused directly into the hepatic arteries where they become lodged within the tumor microvasculature so that the $\beta$-emissions from the isotope can irradiate the tumor. The mean tissue penetration is only $2.5 \mathrm{~mm}$ with a maximum range of $11 \mathrm{~mm}$. Two preliminary studies with 24 and 25 patients have shown favorable initial results for RE, with an overall survival of 9.3 and 14.9 months, respectively [48, 49]. In another trial, 19 patients with unresectable ICC underwent a total of $24 \mathrm{RE}$ [50]. Median survival from the time of diagnosis and first procedure in this population was 25.1 and 11.5 months, respectively. Hoffmann et al. [51] retrospectively investigated RE in 33 patients with unresectable ICC. Most of the patients were pretreated with different therapies. Re- sponse rates after 3 months were: partial response in 12 $(36.4 \%)$ patients, stable disease in $17(51.1 \%)$, and progressive disease in $5(15.2 \%)$. Median overall survival was 22 months. In a large multi-institutional analysis of 198 patients, the effects of various intra-arterial therapies for advanced ICC were evaluated, with RE being applied in 46 patients [52]. Median overall survival in these patients was 11.3 months, which was comparable to conventional TACE, the locoregional therapy most frequently applied in this trial.

\section{Conclusion}

In metastatic disease, chemotherapy improves quality of life and survival, and gemcitabine with cisplatin represents the standard of care. However, all patients ultimately progress on this therapy, so clinical trials with new and better agents are essential to expand the existing treatment options for patients with biliary cancer. Local and locoregional therapies have been shown to be well tolerated and effective in the treatment of CCA, nevertheless their precise role needs to be evaluated in phase III prospective trials.

\section{Disclosure Statement}

The authors disclose that they have no conflicts of interest.

\section{References}

1 Chaiteerakij R, Yang JD, Harmsen WS, Slettedahl SW, Mettler TA, Fredericksen ZS, Kim WR, Gores GJ, Roberts RO, Olson JE, Therneau TM, Roberts LR: Risk factors for intrahepatic cholangiocarcinoma: association between metformin use and reduced cancer risk. Hepatology 2013;57:648-655.

2 Horgan AM, Amir E, Walter T, Knox JJ: Adjuvan therapy in the treatment of biliary tract cancer: a systematic review and meta-analysis. J Clin Oncol 2012;30:1934-1940.

3 Valle JW, Furuse J, Jitlal M, Beare S, Mizuno N, Wasan H, Bridgewater J, Okusaka T: Cisplatin and gemcitabine for advanced biliary tract cancer: a meta-analysis of two randomised trials. Ann Oncol 2014;25:391-398.

4 Dougherty TJ, Gomer CJ, Henderson BW, Jori G, Kessel D, Korbelik M, Moan J, Peng Q: Photodynamic therapy. J Natl Cancer Inst 1998;90:889-905.

5 Ortner ME, Caca K, Berr F, Liebetruth J, Mansmann U, Huster D, Voderholzer W, Schachschal G, Mossner J, Lochs H: Successful photodynamic therapy for nonresectable cholangiocarcinoma: a randomized prospective study. Gastroenterology 2003;125:1355-1363.

-6 Zoepf T, Jakobs R, Arnold JC, Apel D, Riemann JF: Palliation of nonresectable bile duct cancer: improved survival after photodynamic therapy. Am J Gastroenterol 2005;100:2426-2430.
7 Fayter D, Corbett M, Heirs M, Fox D, Eastwood A: A systematic review of photodynamic therapy in the treatment of pre-cancerous skin conditions, Barrett's oesophagus and cancers of the biliary tract, brain, head and neck, lung, oesophagus and skin. Health Technol Assess 2010;14:1-288.

8 Gao F, Bai Y, Ma SR, Liu F, Li ZS: Systematic review: photodynamic therapy for unresectable cholangiocarcinoma. J Hepatobiliary Pancreat Sci 2010;17:125-131.

-9 Leggett CL, Gorospe EC, Murad MH, Montori VM, Baron TH, Wang KK: Photodynamic therapy for unresectable cholangiocarcinoma: a comparative effectiveness systematic review and meta-analyses. Photodiagnosis Photodyn Ther 2012;9:189-195.

10 Valle J, Wasan H, Palmer DH, Cunningham D, Anthoney A, Maraveyas A, Madhusudan S, Iveson T, Hughes S, Pereira SP, Roughton M, Bridgewater J; ABC-02 Trial Investigators: Cisplatin plus gemcitabine versus gemcitabine for biliary tract cancer. N Engl J Med 2010;362:1273-1281.

11 Talreja JP, Degaetani M, Ellen K, Schmitt T, Gaidhane M, Kahaleh M: Photodynamic therapy in unresectable cholangiocarcinoma: not for the uncommitted. Clin Endosc 2013;46:390-394.

12 Pereira S, Hughes SK, Roughton M, O'Donoghue P, Wasan HS, Valle J, Bridgewater J: Photostent-02; Porfimer sodium photodynamic therapy plus stenting versus stenting alone in patients with advanced or metastatic cholangiocarcinomas and other biliary tract tumours: a multicentre, randomised phase III trial. Ann Oncol 2010;21:250.
3 Park DH, Lee SS, Park SE, Lee JL, Choi JH, Choi HJ, Jang JW, Kim HJ, Eum JB, Seo DW, Lee SK, Kim MH, Lee JB: Randomised phase II trial of photodynamic therapy plus oral fluoropyrimidine, $\mathrm{S}-1$, versus photodynamic therapy alone for unresectable hilar cholangiocarcinoma. Eur J Cancer 2014;50:1259-1268.

14 Witzigmann H, Berr F, Ringel U, Caca K, Uhlmann D, Schoppmeyer K, Tannapfel A, Wittekind C, Mossner J, Hauss J, Wiedmann M: Surgical and palliative management and outcome in 184 patients with hilar cholangiocarcinoma: palliative photodynamic therapy plus stenting is comparable to $\mathrm{r} 1 / \mathrm{r} 2$ resection. Ann Surg 2006;244:230-239.

15 Steel AW, Postgate AJ, Khorsandi S, Nicholls J, Jiao L, Vlavianos P, Habib N, Westaby D: Endoscopically applied radiofrequency ablation appears to be safe in the treatment of malignant biliary obstruction. Gastrointest Endosc 2011;73:149-153.

16 Mizandari M, Pai M, Xi F, Valek V, Tomas A, Quaretti P, Golfieri R, Mosconi C, Guokun A, Kyriakides C, Dickinson R, Nicholls J, Habib N: Percutaneous intraductal radiofrequency ablation is a safe treatment for malignant biliary obstruction: feasibility and early results. Cardiovasc Intervent Radiol 2013;36:814-819.

17 De Baere T, Deschamps F, Briggs P, Dromain C, Boige V, Hechelhammer L, Abdel-Rehim M, Auperin A, Goere D, Elias D: Hepatic malignancies: percutaneous radiofrequency ablation during percutaneous portal or hepatic vein occlusion. Radiology 2008;248:1056-1066. 
18 Cho YK, Kim JK, Kim MY, Rhim H, Han JK: Systematic review of randomized trials for hepatocellular carcinoma treated with percutaneous ablation therapies. Hepatology 2009;49:453-459.

19 Stang A, Fischbach R, Teichmann W, Bokemeyer C, Braumann D: A systematic review on the clinical benefit and role of radiofrequency ablation as treatment of colorectal liver metastases. Eur J Cancer 2009:45:1748-1756.

20 Kim JH, Won HJ, Shin YM, Kim KA, Kim PN: Radiofrequency ablation for the treatment of primary intrahepatic cholangiocarcinoma. AJR Am J Roentgenol 2011;196:W205-209.

-21 Schnapauff D, Denecke T, Grieser C, Collettini F, Seehofer D, Sinn M, Banzer J, Lopez-Hanninen E, Hamm B, Wust P, Gebauer B: Computed tomography-guided interstitial HDR brachytherapy (CTHDRBT) of the liver in patients with irresectable intrahepatic cholangiocarcinoma. Cardiovasc Intervent Radiol 2012;35:581-587.

22 Ricke J, Wust P, Stohlmann A, Beck A, Cho CH, Pech M, Wieners G, Spors B, Werk M, Rosner C, Hanninen EL, Felix R: CT-guided interstitial brachytherapy of liver malignancies alone or in combination with thermal ablation: phase I-II results of a novel technique. Int J Radiat Oncol Biol Phys 2004;58:1496-1505.

-23 Ricke J, Mohnike K, Pech M, Seidensticker M, Ruhl R, Wieners G, Gaffke G, Kropf S, Felix R, Wust P: Local response and impact on survival after local ablation of liver metastases from colorectal carcinoma by computed tomography-guided high-dose-rate brachytherapy. Int J Radiat Oncol Biol Phys 2010;78:479-485.

24 Mohnike K, Wieners G, Schwartz F, Seidensticker M, Pech M, Ruehl R, Wust P, Lopez-Hanninen E, Gademann G, Peters N, Berg T, Malfertheiner P, Ricke J: Computed tomography-guided high-doserate brachytherapy in hepatocellular carcinoma: safety, efficacy, and effect on survival. Int J Radiat Oncol Biol Phys 2010;78:172-179.

-25 Ricke J, Wust P, Wieners G, Beck A, Cho CH, Seidensticker M, Pech M, Werk M, Rosner C, Hanninen EL, Freund T, Felix R: Liver malignancies: CT-guided interstitial brachytherapy in patients with unfavorable lesions for thermal ablation. J Vasc Interv Radiol 2004;15:1279-1286.

26 Mahnken AH, Bruners P, Gunther RW: Techniques of interventional tumor therapy. Dtsch Arztebl Int 2008;105:646-653.

27 Endo I, Gonen M, Yopp AC, Dalal KM, Zhou Q, Klimstra D, D'Angelica M, DeMatteo RP, Fong Y, Schwartz L, Kemeny N, O'Reilly E, Abou-Alfa GK, Shimada H, Blumgart LH, Jarnagin WR: Intrahepatic cholangiocarcinoma: rising frequency, improved survival, and determinants of outcome after resection. Ann Surg 2008;248:84-96.

28 Yedibela S, Demir R, Zhang W, Meyer T, Hohenberger W, Schonleben F: Surgical treatment of mass-forming intrahepatic cholangiocarcinoma: an 11-year Western single-center experience in 107 patients. Ann Surg Oncol 2009;16:404-412.

-29 Dhanasekaran R, Hemming AW, Zendejas I, George T, Nelson DR, Soldevila-Pico C, Firpi RJ, Morelli G, Clark V, Cabrera R: Treatment outcomes and prognostic factors of intrahepatic cholangiocarcinoma. Oncol Rep 2013;29:1259-1267.
30 Ricke J, Hildebrandt B, Miersch A, Nicolaou A, Warschewske G, Teichgraber U, Lopez Hanninen E, Riess H, Felix R: Hepatic arterial port systems for treatment of liver metastases: factors affecting patency and adverse events. J Vasc Interv Radiol 2004;15:825-833.

31 Cantore M, Mambrini A, Fiorentini G, Rabbi C, Zamagni D, Caudana R, Pennucci C, Sanguinetti F, Lombardi M, Nicoli N: Phase II study of hepatic intraarterial epirubicin and cisplatin, with systemic 5-fluorouracil in patients with unresectable biliary tract tumors. Cancer 2005;103:1402-1407.

32 Vogl TJ, Zangos S, Eichler K, Selby JB, Bauer RW: Palliative hepatic intraarterial chemotherapy (HIC) using a novel combination of gemcitabine and mitomycin C: results in hepatic metastases. Eur Radiol 2008;18:468-476.

33 Northover JM, Terblanche J: A new look at the arterial supply of the bile duct in man and its surgical implications. Br J Surg 1979;66:379-384.

34 Miller DL, Carrasquillo JA, Lutz RJ, Chang AE: Hepatic perfusion during hepatic artery infusion chemotherapy: evaluation with perfusion CT and perfusion scintigraphy. J Comput Assist Tomogr 1989;13:958-964.

35 Tanaka N, Yamakado K, Nakatsuka A, Fujii A, Matsumura K, Takeda K: Arterial chemoinfusion therapy through an implanted port system for patients with unresectable intrahepatic cholangiocarcinoma - initial experience. Eur J Radiol 2002;41: 42-48.

36 Higashi S, Kato C, Sakumoto H, Sumiyoshi K, Takahahsi T, Matsumoto K, Kane T, Sakoda M, Takahashi M, Hosono Y, Asano M, Yamamoto A: Arterial infusion therapy with implantable port for inoperable hepatobiliary tumors (article in Japanese). Gan To Kagaku Ryoho 1999;26:1764-1767.

37 Melichar B, Cerman J Jr, Dvorak J, Jandik P, Mergancova J, Melicharova K, Touskova M, Krajina A, Voboril Z: Regional chemotherapy in biliary tract cancers - a single institution experience. Hepatogastroenterology 2002;49:900-906.

38 Hong K, Geschwind JF: Locoregional intra-arterial therapies for unresectable intrahepatic cholangiocarcinoma. Semin Oncol 2010;37:110-117.

39 Herber S, Otto G, Schneider J, Manzl N, Kummer I, Kanzler S, Schuchmann A, Thies J, Duber C, Pitton M: Transarterial chemoembolization (TACE) for inoperable intrahepatic cholangiocarcinoma. Cardiovasc Intervent Radiol 2007:30:1156-1165.

40 Vogl TJ, Naguib NN, Nour-Eldin NE, Bechstein WO, Zeuzem S, Trojan J, Gruber-Rouh T: Transarterial chemoembolization in the treatment of patients with unresectable cholangiocarcinoma: results and prognostic factors governing treatment success. Int J Cancer 2012;131:733-740.

41 Kiefer MV, Albert M, McNally M, Robertson M, Sun W, Fraker D, Olthoff K, Christians K, Pappas S, Rilling W, Soulen MC: Chemoembolization of intrahepatic cholangiocarcinoma with cisplatinum, doxorubicin, mitomycin $\mathrm{C}$, ethiodol, and polyvinyl alcohol: a 2-center study. Cancer 2011;117:1498-1505.
42 Park SY, Kim JH, Yoon HJ, Lee IS, Yoon HK, Kim KP: Transarterial chemoembolization versus supportive therapy in the palliative treatment of unresectable intrahepatic cholangiocarcinoma. Clin Radiol 2011;66:322-328.

43 Poggi G, Amatu A, Montagna B, Quaretti P, Minoia C, Sottani C, Villani L, Tagliaferri B, Sottotetti F, Rossi O, Pozzi E, Zappoli F, Riccardi A, Bernardo G: OEM-TACE: a new therapeutic approach in unresectable intrahepatic cholangiocarcinoma. Cardiovasc Intervent Radiol 2009;32:1187-1192.

44 Aliberti C, Benea G, Tilli M, Fiorentini G: Chemoembolization (TACE) of unresectable intrahepatic cholangiocarcinoma with slow-release doxorubicineluting beads: preliminary results. Cardiovasc Intervent Radiol 2008;31:883-888.

45 Kuhlmann JB, Euringer W, Spangenberg HC, Breidert M, Blum HE, Harder J, Fischer R: Treatment of unresectable cholangiocarcinoma: conventional transarterial chemoembolization compared with drug eluting bead-transarterial chemoembolization and systemic chemotherapy. Eur J Gastroenterol Hepatol 2012;24:437-443.

46 Vente MA, Wondergem M, van der Tweel I, van den Bosch MA, Zonnenberg BA, Lam MG, van Het Schip AD, Nijsen JF: Yttrium-90 microsphere radioembolization for the treatment of liver malignancies: a structured meta-analysis. Eur Radiol 2009;19:951-959.

47 Kennedy AS, Salem R: Radioembolization (yttrium-90 microspheres) for primary and metastatic hepatic malignancies. Cancer J 2010;16:163-175.

48 Ibrahim SM, Mulcahy MF, Lewandowski RJ, Sato KT, Ryu RK, Masterson EJ, Newman SB, Benson A 3rd, Omary RA, Salem R: Treatment of unresectable cholangiocarcinoma using yttrium-90 microspheres: results from a pilot study. Cancer 2008; 113:2119-2128.

49 Saxena A, Bester L, Chua TC, Chu FC, Morris DL: Yttrium-90 radiotherapy for unresectable intrahepatic cholangiocarcinoma: a preliminary assessment of this novel treatment option. Ann Surg Oncol 2010;17:484-491.

50 Rafi S, Piduru SM, El-Rayes B, Kauh JS, Kooby DA, Sarmiento JM, Kim HS: Yttrium-90 radioembolization for unresectable standard-chemorefractory intrahepatic cholangiocarcinoma: survival, efficacy, and safety study. Cardiovasc Intervent Radiol 2013;36:440-448.

51 Hoffmann RT, Paprottka PM, Schon A, Bamberg F, Haug A, Durr EM, Rauch B, Trumm CT, Jakobs TF, Helmberger TK, Reiser MF, Kolligs FT: Transarterial hepatic yttrium-90 radioembolization in patients with unresectable intrahepatic cholangiocarcinoma: factors associated with prolonged survival. Cardiovasc Intervent Radiol 2012;35:105-116.

52 Hyder O, Marsh JW, Salem R, Petre EN, Kalva S, Liapi E, Cosgrove D, Neal D, Kamel I, Zhu AX, Sofocleous CT, Geschwind JF, Pawlik TM: Intraarterial therapy for advanced intrahepatic cholangiocarcinoma: a multi-institutional analysis. Ann Surg Oncol 2013;20:3779-3786.

53 Khan SA, Davidson BR, Goldin RD, Heaton N, Karani J, Pereira SP, Rosenberg WM, Tait P, Taylor-Robinson SD, Thillainayagam AV, Thomas HC, Wasan H; British Society of Gastroenterology: Guidelines for the diagnosis and treatment of cholangiocarcinoma: an update. Gut 2012;61:16571669. 